\title{
Perception of Faculty and Students About E Learning About Feasibility, Acceptance and Implementation in Covid Crisis
}

Pramila Menon ( $\nabla$ pramila_menon@rediffmail.com)

Dr. D Y Patil Medical College, Hospital and Research Centre Dr.D Y Patil Vidyapeeth, Pune, Maharashtra, India https://orcid.org/0000-0002-7780-335X

Vineeta Pande

D Y Patil Medical College

Sudhir Jadhav

D Y Patil Medical College

Sharad Agarkhedkar

D Y Patil Medical College

Research article

Keywords: E learning, google classroom, video based platforms

Posted Date: August 26th, 2020

DOI: https://doi.org/10.21203/rs.3.rs-42343/v1

License: (9) This work is licensed under a Creative Commons Attribution 4.0 International License. Read Full License 


\section{Abstract}

The study aimed to understand the perception, acceptance and feasibility of E learning for undergraduate medical students and faculty during the Carona pandemic and get suggestions to improve the teaching learning process.

Methods: Total $447(436+11)$ were approached for the response through google form. Out of 447 participants of 321 responses ( 71\%; $95 \mathrm{Cl}$ 67.5-75.8) recorded and 302 (96\%; $95 \mathrm{Cl}$ 90.9-96.4) gave consent which included (students 211 and 11 faculty) who experienced E learning as teaching learning method and their feedback collected using an semi structured questionnaire as google form in google classroom.

Results: A majority $81 \%$ ( $95 \mathrm{Cl} 67.5-75.8$ ) had positive responses towards various aspects of the online classes. Google classroom and video based platforms like zoom,cisco webex, google meet were the most preferred and convenient platforms.

Conclusion: Online classes were accepted by the most of the students and faculty. The positive feedback and suggestions helped in the planning of E learning classes in the existing curriculum for future.

\section{Background}

Medical graduates of the twenty-first are expected to be up-to-date with latest technology. MCI Medical Council of India (MCl), Vision 2015 has included the use of E learning to achieve the broad competency "Lifelong learner committed to continuous improvement of skills and knowledge (1).Technology assisted E learning gives flexibility to the learner in today's fast dynamic world. The need of hour is digitally literate teachers and students to incorporate this teaching learning method in existing curriculum. $E$ learning can be defined as the use of electronic technology as teaching learning method which involves interaction with teachers and learners. It provides easy and effective information to students (2).Due to Corona virus pandemic on campus lectures and training in medical college was suspended. This led to the need for online classes hence E learning platform was explored. To understand the feedback of faculty and students, this study was planned.

\section{Methods}

Corona pandemic disrupted regular classes in the medical college which made teachers to go for alternatives. To reach the students and complete the syllabus for the term, online teaching sessions were planned. Faculty and students were trained through video-based platform like zoom free version, cisco webex, skype, google classroom and google groups. There were 11 faculty and 436 undergraduate students of pediatrics department. We used a free version of Zoom which allows maximum of 100 participants and for time period of $40 \mathrm{~min}$. Permission for the study was obtained from the institutional ethics committee. Consent was included in google form which was sent on online platform. 
To understand teachers' and students' perspective about online teaching, survey was conducted for 447 which included 11 faculty and 436 students of pediatrics department. Google form was created to get feedback to understand the perception of students and faculty about online classes.Data were recorded on a Google excel sheet and analyzed using SPSS version 26.

\section{Results}

The sessions were attended by 436 students on google classroom and video sessions by $80-100$ students in groups. Assignments were part of teaching by using google forms. The response rate was 71.4\%\% (95 Cl 67.5-75.8). 81\% (95 Cl 67.5-75.8) participants are happy about online teaching learning (53\% plus $27.9 \%$ as $27.9 \%$ said may be which was also not negative so included as positive response).52.9\% (95 Cl;47.3-58.6) are using google classroom,32.2\% (95 Cl;27-37.6) are using video based platforms like zoom, google meet, cisco web etc . 53.6\% (95 Cl; 48-59.2) participants felt google classroom and $44.1 \%$ ( $95 \mathrm{Cl} ; 38.5-49.7)$ opined that video based platform as the best platform for teaching learning. The students responded to online classes as more comfortable way of study in Carona pandemic. We do not need to travel and it also makes sure that no harm to studies during corona crisis. It follows principle of physical distancing. Students felt that they can redo the things by correcting their mistakes, better utilization of time and time management. This type of teaching makes the day more productive and keeps the one occupied. Students felt that E learning is allowing them learn at their own pace and schedule.

The advantages of E learning described by $77.1 \%$ participants $(95 \mathrm{Cl} ; 72.2-81.6)$ included flexibility $28 \%$, convenient $33 \%$,helps in revision $9 \%$, helpful in pandemic $18 \%$ with social distancing. About $10 \%$ participants said no advantages of E learning. Both students and faculty felt it saves travel time and useful in pandemic.

The difficulties associated with E learning cited by $82.5 \%$ participants $(95 \mathrm{Cl} ; 77.9-86.4)$ listed network issues and technical issues with data limitations $31 \%$, less interaction $15 \%$, eye strain $5 \%$ and $16.5 \%$ did not have any problem.

Our faculty also felt E learning was very difficult initially and were not ready but day by day, they were learning something new so experience became better than the previous one. They felt students do not respond at times and difficult to understand their concerns and difficult to monitor. Faculty felt it is not good for regular syllabus because psychomotor skills are difficult to teach. It is good for theory classes but not practical for patient in respect to clinical aspect. The difficulties faced were limitation on the number of participants who can participate the sessions, limited time for the sessions, and technical errors like network problems. Our experience shows the senior faculty were more motivated and encouraging than the junior faculty. They got trained first and made junior faulty to follow which made the teaching learning process of E learning easy. It may be due to the need of the hour.

some of the reactions of the students. 
"The recorded lecture can be viewed by me/others any number of times. I can watch the lectures in my own comfort at my own pace. There is no disturbance from the other students. This is the only cost effective and eco-friendly way of learning. Attending lectures comfortably, Convenient,also helps to concentrate. Time efficient and ppt are available after most lectures. It is just helping to be in touch with the subject! Flexibility"

"You can redo the things by correcting your mistakes On platforms like Google classroom, you can rewind , fast forward, etc which helps me understand the topic better"

"I accept it comes with it's own disadvantages but I feel this is a great way of learning from the comfort and safety of our homes. On platforms like zoom and WebEx, if you have a bad connection, you won't understand the topic. Therefore I think that recorded lectures are better."

Online google classes gives less disturbance and is a comfortable learning method during pandemic makes. Staying in touch with the subject Learning from any place around the world possible is the biggest advantage. The resources are available anywhere and anytime help to revise all points in short time.

Safe, Its very interesting, Interactive, one to one learning, convenient program and learning process

It gives a better experience and better understanding even at home. The students have feeling of

personalization of study material. Online classes are better utilization of time and time management and also reduces travel time and has reduced the pressure that we used to have while attending college. It wastes less time of the students. This is the only cost effective and eco-friendly way of learning.

Disadvantages:

Few students felt E- learning so far has not been very fruitful. What they had in their traditional classroom learning helped them to have one on one interaction with the lecturer and gave the environment to learn and have their doubts cleared. It is understandable that with the given circumstances e learning is the best option. There were suggestions by $64.9 \%$ (95 Cl;59.4-70.1) participants for video-based platform recorded lectures, more assignment and discussion interaction, buy platform which can accommodate more participants and better network and monitoring students. These problems were addressed later on by buying advanced version of the software that allows unlimited time and the suggestions given by the students were to upload a recorded video lecture so that they get better explanation of the topic. They wanted it more interactive and exam oriented and put previous years question papers which will help us prepare better. They wanted videos of actual patients and how doctors are coming up with a treatment plan and mange the patients in reality which will help us to learn better. It's a need of today but should not replace time tested real teaching at least in medical field. Suggestions by the students included that parts of e-learning should be adapted into normal teaching. Though there is no comparison with traditional teaching but online classes are useful in periods of lockdown for the sake of physical distancing. 


\section{Discussion}

The success of online teaching learning depends on many factors. Both students' and teachers' perspectives are important to make it effective $(3,4)$. "cultural resistances" of staff towards E learning is identified as a barrier to student engagement with technology-based education hence faculty orientation and training them in E learning is very important initiatives to the introduction of successful e-learning programs. We did as part of our medical education activity. Our faculty felt it was very difficult initially and reluctant initially but day by they were learning something new so experience became better than the previous one. But they felt the students do not respond at times and difficult to understand if they have concerns or not. It is good for theory classes but not practical for patient in respect to clinical aspect. WHO, UNICEF report 2017 suggested that online learning is feasible and effective for training health care professionals in acquiring knowledge and skills related to essential newborn care. Nearly 3500 physicians and over 1000 nursing professionals were trained in 12 sick newborn care courses and five essential newborn care courses $(5,6)$

Technology now plays an important role in educational transformation. The online learning platforms provide a reasonable combination of accessibility of knowledge with learner flexibility and interactivity. This learner centered approach, also called asynchronous e-learning (7) can help balance professional development with personal and work commitments. Our students' response also very similar to this study. Stewart, et al. 2013 found that the group of medical students who received blended learning which had an online component, in addition to the conventional teaching, achieved a significantly higher mean score in a module for teaching newborn physical examination skills than the control group (8). This was also suggestion from our students to include online classes even after lockdown period as google classroom gives them personalization of resources. E-learning has been an important aspect of the current undergraduate curriculum delivery wherein reports of shortage of medical teachers have been reported(9).The adoption of the same within the medical colleges is expected to promote self directed learning and lifelong learning. Thus it will benefit both the teachers as well as the students (10). Similar

experience shared by Scagnoli et al shows the importance of online training in COVID pandemic pediatric undergraduate students (11). Flexibility of E learning which can provide information to the students beyond the specified timings of teaching in class and gives freedom to read and learn whenever they feel the need for the same was documented in Nigeria study. Our students also highlighted this point (12). Apart from fruitful use of the lockdown period in the corona pandemic, the present study revealed the acceptance of online learning by the students and faculty with few suggestions.

\section{Conclusion}

We conclude that online teaching is possible and acceptable complementary method to traditional medical teaching in India beyond lockdown period. The study will be helpful in planning online classes for undergraduate students in medical education.

\section{Abbreviations}


$\mathrm{MCl}$ - Medical Council of India, WHO World Health Organization UNICEF :United Nations Children Emergency Fund

\section{Declarations}

Ethics approval and consent to participate: Yes Competing Interests: None Acknowledgment : Dean of Dr

D Y Patil Medical College Hospital and Research centre Pune

Data and material available with department

Consent for publication : Yes Funding : None

\section{References}

1. MCI Vision 2015 Booklet. Medical Council of India. Available from: ww.mciindia.org/tools/announcement/ MCl_booklet.pdf. Accessed June 18, 2016

2. Mooney G, Bligh J. Information technology in medical education: current and future applications a shift in medical education practice from traditional forms of teaching to other media which employ online, distance or electronic learning

3. Greenhalgh T. Computer assisted learning in undergraduate medical education.BMJ (Clinical Research Edition). 2001;322(7277):40-4.

4. Bediang G, Stoll B, Geissbuhler A, Klohn A, Stuckelberger A, Nko'o S, et al.Computer literacy and elearning perception in Cameroon: the case of Yaounde Faculty of Medicine and Biomedical Sciences. BMC Med Edu.2013;13(57):1-8.

5. Reaching the Every Newborn National 2020 Milestones Country Progress, Plans and Moving Forward Geneva: World Health Organization. WHO, UNICEF report 2017. Accessed October 1, 2017.

6. Thukral A, Sasi A, Chawla D, Datta P, Wahid S, Rao S, et al. Online neonatal training and orientation programme in india (ontop-in) $-1 /$ nthe way forward for distance education in developing countries. $J$ Trop Pediatr. 2012;58:486-9.

7. Dobrow MJ, Neeson J, Sullivan T. Canadian chief executives' prescription for higher quality: more clinical engagement, shared accountability and capacity development. Healthc Q. 2011;14:18-21.

8. Stewart A, Garry I, Jardine L, Pieter K, Davies, William M. A randomised controlled trial of blended learning to improve the newborn examination skills of medical students. Arch Dis Child-Fetal Neonatal Ed. 2013;98:F141-4

9. Dhir SK, Verma D, Batta M, Mishra D. E-learning in medical education in India. Indian Pediatr. 2017; 54:871-7.

10. Vaona A, Banzi R, Kwag KH, Rigon G, Cereda D, Pecoraro V et al. E-learning for health professionals. Cochrane Database Syst Rev 2018;1:CD011736. 
11. Scagnoli NI, Choo J, Tian J. Students' insights on the use of video lectures in online classes. $\mathrm{Br} \mathrm{J}$ Educ Technol. 2019;50:399-414

12. 3. Obi IE, Charles-Okoli AN, Agunwa CC, Omotowo BI, Ndu AC, Agwu-Umahi OR. E-learning readiness from perspectives of medical students: a survey in Nigeria. Niger J Clin Pract 2018;21:293-300. 